\title{
Achieving restoration targets and addressing completion criteria with remote sensing
}

\author{
C Richardson Alcoa of Australia Ltd, Australia \\ AH Grigg Alcoa of Australia Ltd, Australia \\ T Robinson Curtin University, Australia \\ G Wardell-Johnson Curtin University, Australia
}

\begin{abstract}
Alcoa of Australia has undertaken a progressive post-mining restoration program following bauxite mining in the jarrah forest of south-western Australia since operations began in 1963. Approximately 10,000 ha of restored forest is now of a suitable age for assessment and sign-off against agreed rehabilitation completion criteria. Remote sensing techniques have the potential to efficiently measure a range of attributes of post-mining restoration over areas of this size. We used airborne laser scanning and multispectral imagery from remotely piloted aircraft to estimate a range of forest canopy attributes. We also used these approaches to penetrate established tree canopies and measure understorey and the underlying terrain at very high resolution $(e . g .40 \mathrm{~cm})$. We also used vegetation indices derived from Landsat satellite imagery for chronosequence assessment dating from the early 1970s. This paper describes investigations into the potential of these remote sensing techniques for assessment of older restoration and implementation within a process for sign-off with government. Field-based calibration is an essential component of these studies, and comparisons of on-ground measurement of vegetation structure and cover with remotely sensed indices are presented.
\end{abstract}

Keywords: remote sensing, restoration trajectory, LiDAR, multispectral imagery, mining restoration, completion criteria, jarrah forest

\section{Introduction}

Alcoa of Australia (Alcoa) commenced bauxite mining near Jarrahdale (Figure 1) in the northern jarrah (Eucalyptus marginata) forest of south-western Australia in 1963. The Jarrahdale mine ceased operation in 1998 and was fully decommissioned in 2001; however, the Huntly and Willowdale mines located near Dwellingup (Figure 1) are anticipated to continue operating until 2045. Alcoa undertakes a progressive rehabilitation program, restoring approximately 600 ha of forest after mining each year. To date, there are approximately 10,000 ha of restored forest that Alcoa considers of a suitable age for final sign-off with government using agreed completion criteria. Best practice restoration of bauxite mined sites should include a reassessment of existing restoration and re-establishment of the understorey (Wardell-Johnson et al. 2015). To effectively assess the quality of these areas and provide evidence of restoration efforts, remote sensing techniques offer the potential to rapidly assess large areas of forest and restored forest comprehensively and efficiently.

In this paper, novel methods are presented that derive several forest structural characteristics and topographical attributes from airborne light detection and ranging (LiDAR), multispectral imagery and Landsat remotely sensed datasets. Increasing affordability and accessibility to remote sensing technology allowed this investigation to address completion criteria by:

- Assessing the structure (vertical and horizontal vegetation cover) of restoration and the surrounding unmined forest. 
- Detecting individual trees for estimation of stand density and canopy heights.

- Staging restoration on a trajectory to a forest reference.

- Identifying surface terrain features such as erosion gullies underneath vegetation cover.

The methods are adaptable to a range of forest structures, including mixed-age stands, different forest types within the northern jarrah forest, and to even-aged regrowth stands of varying age since mining and restoration. Applying these new techniques is consistent with Alcoa's commitment to study the baseline native ecosystem and the restored ecosystem, and to seek convergence in similarity of biodiversity and function (Grant \& Koch 2007).

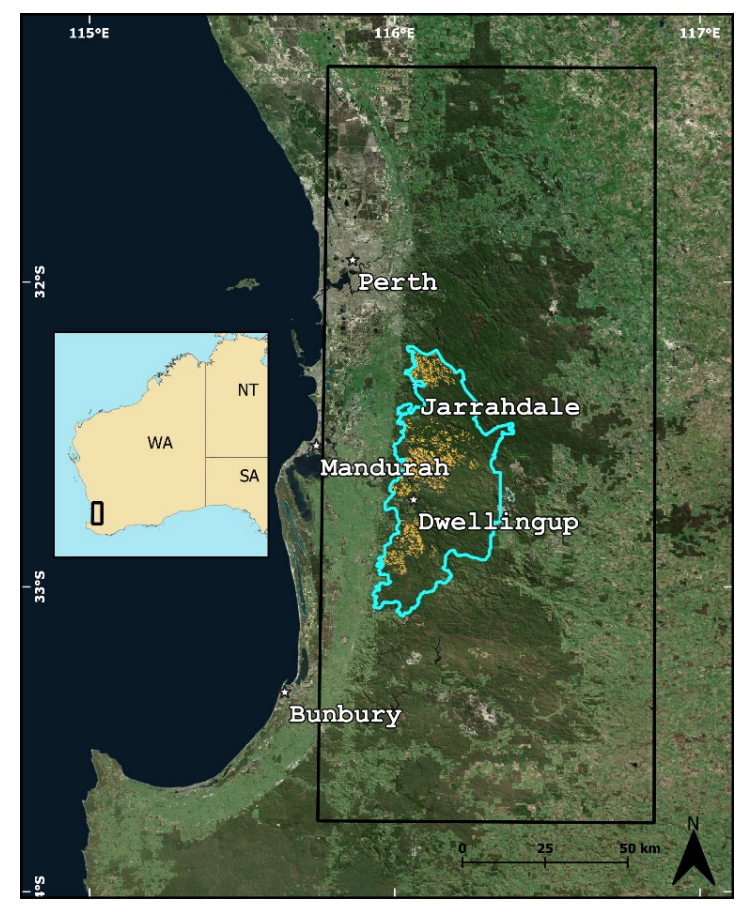

Figure 1 The study area is located in south-western Australia (inset). The light blue outline indicates the extent of the LiDAR data used for this study. The black rectangle is the extent of the Landsat imagery used in this study. The dark green areas shown on the satellite image and bound by the Landsat extent is the northern jarrah forest. Areas that are coloured yellow have undergone post-mining forest restoration. This map was created using the World Imagery basemap within ArcGIS ${ }^{\circledR}$ software by Esri

\section{Alcoa's mine rehabilitation completion criteria}

Alcoa developed completion criteria against which its bauxite mine rehabilitation could be assessed jointly with government in the late 1990s (Elliot et al. 1996). The completion criteria are reviewed and updated approximately every five years to incorporate improvements in knowledge and changing expectations (Department of State Development 2015). The present set of criteria describes 30 specific targets across four phases of pre-mine planning ( $n=9$ criteria), rehabilitation earthworks ( $n=7$ criteria), early vegetation establishment ( $n=5$ criteria) and longer-term vegetation development ( $n=9$ criteria). Of the 30 criteria, the remote sensing techniques described in this study provide evidence for a total of nine criteria, all of which posed logistical challenges to effectively and accurately measure at the scale required. Five of these apply at the earthworks phase and relate to maximum slope gradients, ground fauna habitats, contour ripping, erosion features and bare ground. The remaining four criteria relate to tree stocking rates, timber production potential, resilience to fire, tree thinning and the presence of understorey. All nine criteria align with Alcoa's objective of re-establishing a stable, self-sustaining jarrah forest ecosystem (Grant \& Koch 2007) and address characteristics influencing ecological restoration (Cross et al. 2018; Wardell-Johnson et al. 2015). 


\section{Data acquisition}

\subsection{Airborne laser scanning}

LiDAR data from airborne laser scanning (ALS) was acquired from an Optech ALTM 3100 using a fixed-wing aircraft. This equipment was able to produce four discrete returns within a footprint diameter of approximately $20 \mathrm{~cm}$. The average spacing of points is approximately $40 \mathrm{~cm}$. The extent of the LiDAR data covers approximately $2,000 \mathrm{~km}^{2}$ of northern jarrah forest (Figure 1) that contains all of Alcoa's forest restoration, including those areas planned for final assessment and sign-off.

\subsection{Remotely piloted aircraft}

This study used lightweight commercial multirotor remotely piloted aircraft (RPA) fitted with an aftermarket multispectral sensor. This RPA is capable of undertaking manual and automated aerial surveys and was used to collect photogrammetry and multispectral data for this study. The portability of the lightweight multirotor RPAs gives them an advantage over larger RPAs in remote and rugged forested terrain. The RPA surveyed the plots described in this study to produce high-resolution canopy height models (CHMs) and normalised difference vegetation index (NDVI) imagery. The resolution of these outputs is approximately $2-5 \mathrm{~cm}$. This is much greater than the resolution of imagery that can be produced from ALS. However, the pixel cloud from the RPA multispectral sensor does not penetrate the forest canopy as well as laser pulses from an ALS and therefore is not able to capture certain forest structure characteristics that are possible with LiDAR data.

It is possible to collect ALS data with larger industrial RPAs that carry heavier payloads. This upscaled equipment, in addition to the LiDAR technology, makes this technique more expensive and difficult to operate in remote and rugged forested terrain. However, it could be a viable option for smaller areas and allow for the measurement of understorey otherwise difficult to measure and concealed by the overstorey. Compared with piloted fixed-wing ALS collection techniques, a 100-fold greater resolution using RPA mounted ALS sensors can be achieved. The magnitude of resolution achieved with this technique requires similar processing capabilities as needed for RPA photogrammetry; however, the detail in three dimensions that can be rendered is more comprehensive. In the jarrah forest it would be possible to identify individual tree stems, measure their diameter at breast height (DBH) and bole lengths.

Unlike the ALS technique used for this study, the RPAs were not able to effectively cover large areas, only surveying an area of $\sim 100$ ha per day. This takes into account maintaining line of sight during the survey and access to multiple take-off locations. A larger RPA requires a larger, heavier battery capacity to sustain the increase in weight; as a result, this does not necessarily increase flight time or survey area. The size of upscaled equipment also increases transition time between take-off locations. Many take-off locations that are suitable for the smaller $(<2 \mathrm{~kg})$ RPAs are not necessarily suitable for larger RPAs due to surrounding vegetation and insufficient flat ground. When comparing multirotor RPAs with fixed-wing RPAs, in most of the jarrah forest, a fixed-wing aircraft cannot take off or land without the necessary clear areas for their gradual climbs and descents.

\subsection{Landsat imagery}

This study used a standardised annual time series of leaf area index (LAI) for the northern jarrah forest developed by Macfarlane et al. (2017) from level 1, terrain-corrected Landsat imagery sourced from the United States Geological Survey. The information made available from this technique dates back to 1972. The resolution of this imagery is $60 \mathrm{~m}$ for the years 1972 to 1988 and $30 \mathrm{~m}$ thereafter. The ability to retrospectively measure LAI for a selected area over this period allows the assessment of the resilience of restored areas to disturbance events, such as fire, and the trajectory of restored areas towards their pre-mining forest state to be tracked. 


\section{$4 \quad$ Ground measurements for calibration and validation}

\subsection{Sample site selection}

Plots, with the dimensions $20 \mathrm{~m} \times 20 \mathrm{~m}$, were established in restored areas $(n=37)$ that ranged in age from five to 30 years since establishment. Additional plots $(n=9)$ were established in unmined forest stratified by 'Havel' site vegetation types (Havel 1975). The majority of Alcoa's mining activity takes place in Haveltype combinations of S, P and T (Koch 2007). These site types are located on the upper slopes in gravelly sandy soil and consist of both jarrah and marri (Corymbia calophylla). The $\mathrm{S}$ vegetation site type has an overstorey dominated mostly by jarrah; the T type is dominated by both marri and jarrah and has a loamier soil than the $\mathrm{S}$ type. The $\mathrm{P}$ type has a higher concentration of western sheoaks (Allocasuarina fraseriana) and is found in sandier soils (Havel 1975). Based on the species composition differences in these vegetation site types it is expected that the forest structure will also differ. Here, we measure the variations of forest structure characteristics between the vegetation site types and relate these with outputs from the remotely sensed forest structure characteristics.

\subsection{Tree measurements}

All plots had their locations and dimensions accurately recorded using real-time kinematic positioning. The centre of each plot is used as a base to measure the distance and direction of each tree within the plot using an ultrasonic range finder and a compass with a viewfinder. The trees are later spatially mapped according to these measurements. Each tree taller than $2 \mathrm{~m}$ had its species, DBH, canopy top height and canopy depth recorded.

\subsection{Understorey measurements}

Understorey measurements of height, cover and dominant species were collected using a point centre quarter (PCQ) method on a $3 \times 3 \mathrm{~m}$ grid around the centre of each tree measurement plot. For each sample location the PCQ method is repeated at $0 \mathrm{~m}-0.5 \mathrm{~m}, 0.5 \mathrm{~m}-1 \mathrm{~m}, 1 \mathrm{~m}-2 \mathrm{~m}$ and $2 \mathrm{~m}-3 \mathrm{~m}$ height intervals. At each interval, the first plant intersected with the PCQ method had its species recorded and horizontal and vertical dimensions measured.

\subsection{Canopy cover and leaf area index}

Canopy LAI was estimated by digital canopy photography using the methods of Macfarlane et al. (2007). A total of nine images were collected in each plot on the same $3 \times 3 \mathrm{~m}$ grid used for the understorey measurements. Images were processed using an image-editing program to calculate the mean LAI for each plot (Pekin \& Macfarlane 2009).

\section{$5 \quad$ Assessing forest structure from remotely sensed data}

\subsection{Stratification}

In both the restored forest and the surrounding unmined forest, measurements of vegetation height and vegetation cover in the strata comprise both understorey and overstorey canopies. The LiDAR data were used to create volumetric pixels (voxels) for the sample sites (Schut et al. 2014). The percentage of filled voxels (PFV) is used to measure the presence or absence of vegetation for each $1 \mathrm{~m}$ height interval within the sample area (Figure 2). This process recognises the vertical and horizontal assemblages of vegetation, making it a useful tool to compare the structure among the different forest types and ages. This is validated with field-collected understorey canopy heights, overstorey canopy heights and cover measurements.

The overstorey canopy is defined in this study as any plant greater than $2 \mathrm{~m}$ in height. This specified canopy comprises mostly eucalypts. The shorter trees fill the voids between the taller dominant tree canopies. This varies across the landscape, posing difficulties in separating shorter and taller trees from remote sensing 
data. As a result, the different tree canopies are not distinguished in this study. In taller forest structures, it is possible to differentiate the individual tree canopy depths by identifying changes in the distribution of pulses within the height profile (Jaskierniak et al. 2011).

The understorey vegetation is distinguished from LiDAR data by measuring the PFVs that are distributed in the height profile below the base of the overstorey's PFV distribution. The presence of understorey is a criterion in the completion criteria. Measuring the understorey in established restored forest without the use of LiDAR poses many challenges at a large spatial scale. This investigation allowed for the measurement of understorey in all areas and compares these densities and heights with the surrounding forest (Figure 2).

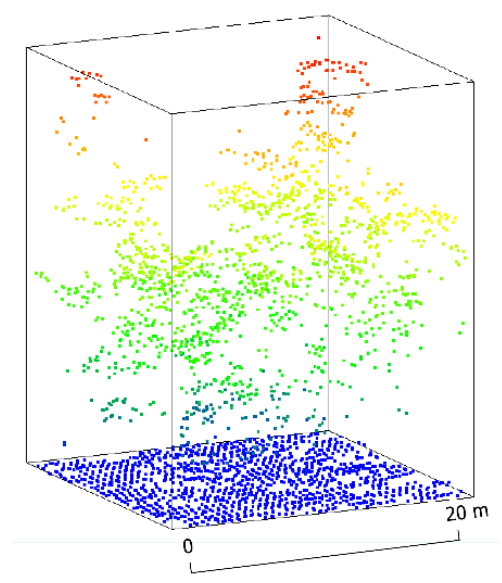

(a)

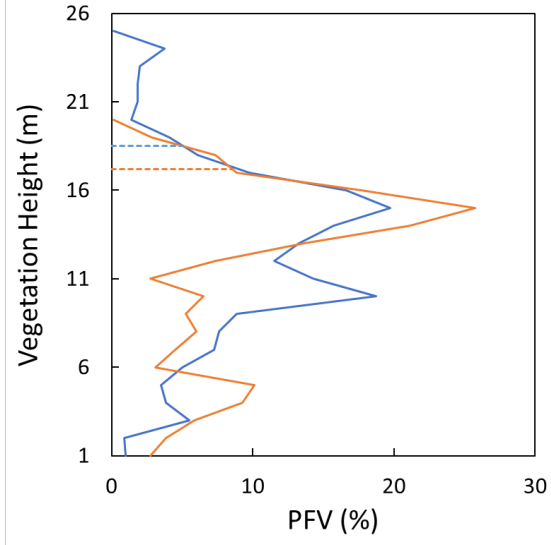

(b)

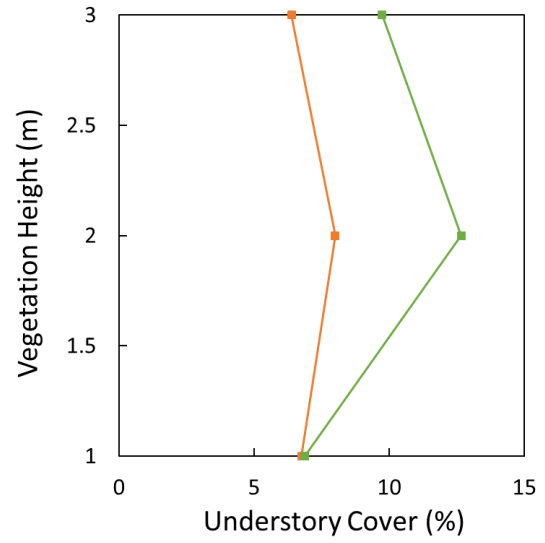

(c)

Figure 2 (a) A 3D view of the pulse distribution for a forest reference plot; (b) The vertical distribution of PFV for unmined jarrah forest (blue) compared to a 29-year-old mined jarrah forest under restoration (orange), with dotted lines indicating the height cutoff for the tallest 90th percentile of trees; (c) The field validation (green) of percentage cover for understorey at different height intervals in 11-year-old mined jarrah forest under restoration (orange)

\subsection{Overstorey characteristics}

\subsubsection{Tree height}

Tree height was estimated using a CHM created from LiDAR data as a grid generated by the triangulation of highest points. To optimise the CHM for tree detection modelling, a triangular irregular network (TIN) was created at different intervals within the vertical profile from pulses allocated with a $10 \mathrm{~cm}$ footprint. These TINs, converted to grids, were then merged to form one grid containing the highest of the overlapping grid values (Khosravipour et al. 2014). The CHMs generated from RPA photogrammetry are also included in this study, although no optimisation of the grid is required as the resolution is fine enough for tree detection modelling. Where trees are identified the matching pixels are used to calculate tree height. Other canopy height measurements used in this investigation use all the pixels from a CHM or all LiDAR point data within a sample area to calculate the average canopy height and tallest 90th percentile of trees.

\subsubsection{Tree density}

Tree density can be estimated from LiDAR data using a CHM or by using a 3D approach on the LiDAR point cloud (Jaskierniak et al. 2015). Detecting individual trees using remote sensing has had varying levels of success in different forest types (Eysn et al. 2015; Pirotti et al. 2017). A multi-aged eucalypt forest poses many challenges when attempting to detect and consolidate canopies into individual trees. This investigation developed a tree detection model that uses a combination of 3D overstorey pulse densities and individual canopy peaks identified from a $\mathrm{CHM}$. The model was found to closely predict tree densities in both unmined forest and restored mined forest (Figure 3). 


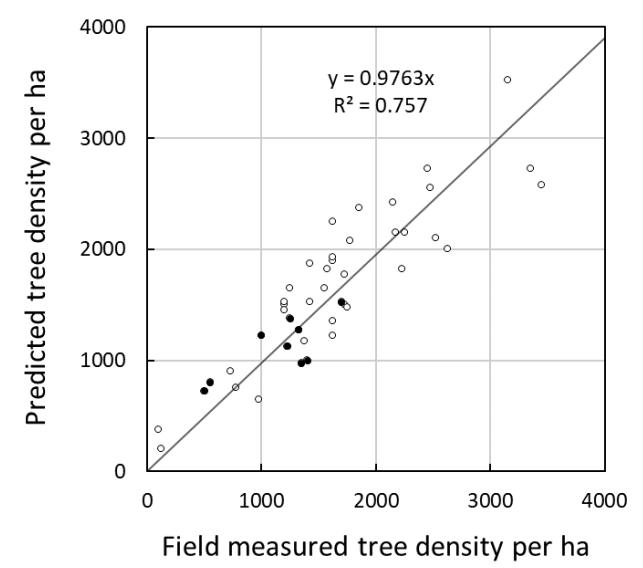

Figure 3 The accuracy of the tree detection model in estimating tree stocking rates, with black circles showing forest plots and white circles showing restored forest plots; the line of best fit is forced through the origin

\subsubsection{Tree positioning}

Positioning the trees to match field spatial measurements proved challenging for the tree detection model in this study. The model uses the canopy to detect individual trees; however, positioning of trees in the field was taken at the stem. In many cases, the canopy apex does not reflect the position of the stem if the form of the tree is not symmetrical or the tree is on a lean. In the example provided in Figure 4, the tree detection model estimated 60 trees for a 1996 restored forest plot, compared with a total of 57 from field measurements.

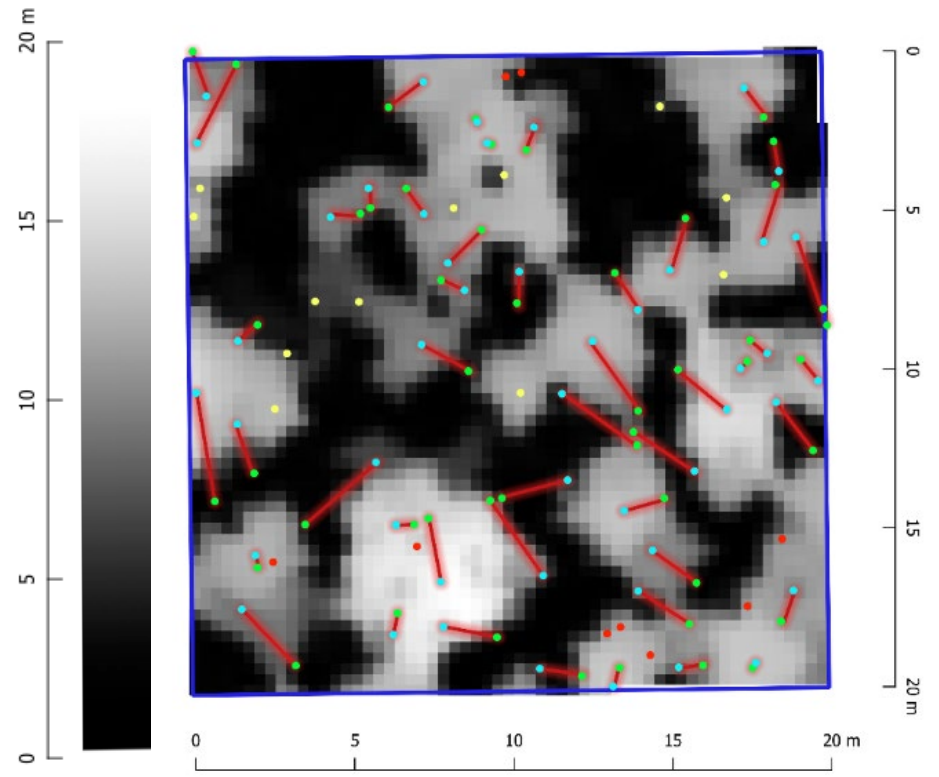

Figure 4 Trees detected by the model (blue circles) matching $84.2 \%$ of field-measured trees (green circles) with the model's $15.8 \%$ omissions (red circles) and $25 \%$ commissions (yellow circles) superimposed over the CHM (height-to-colour gradient provided)

\subsubsection{Site quality index}

The site quality index is defined in this study as the tallest 90th percentile of trees from the tree density model, LiDAR point cloud or CHM. This characteristic is used as a quality indicator when compared with the benchmark for the respective age of restored forest. Figure 5 shows the accuracy of the tree detection model in predicting the tallest 90th percentile of trees when compared with field validation measurements. 


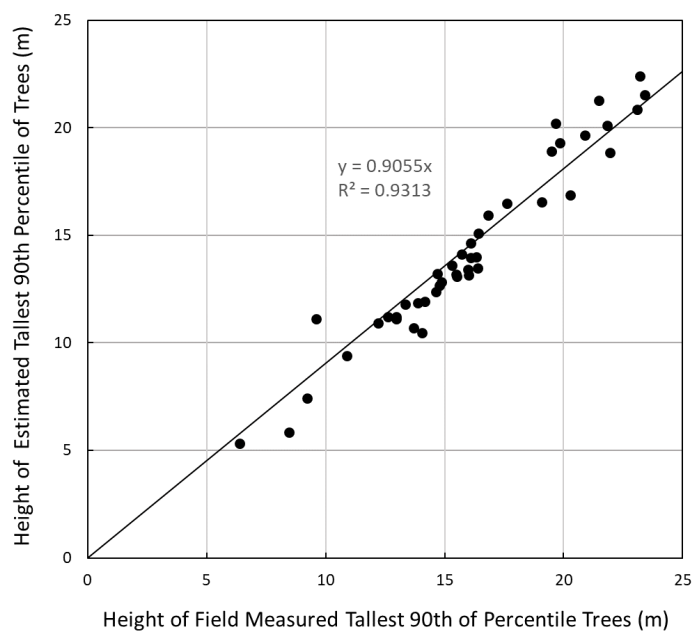

Figure 5 Accuracy of the tree detection model to predict the tallest 90th percentile of trees; the line of best fit is forced through the origin

\subsubsection{Veteran trees}

It was necessary to consider scattered tall veteran trees in the tree detection model. These trees are typically taller than the surrounding vegetation with distinctly broad open canopies with large gaps between individual branch canopies (Abbott \& Loneragan 1986), reflecting their age and history of disturbance from fire, drought, disease and exposure. This has led to burnt out trunks, broken limbs and irregular growth forms. This presents challenges to any tree detection model, as substantial branches from irregular growth forms can be misinterpreted by tree detection models as different trees. The red pulses in Figure 2 indicate trees that meet this categorisation. These trees are identified in the tree detection model used in this study based on their height and receive different canopy consolidation parameters.

\subsubsection{Canopy cover}

Canopy cover is measured as the proportion of pixels from the LiDAR-derived CHM above $2 \mathrm{~m}$ (Figure 6). Overstorey canopy cover is a component of forest structure measuring the density of lateral growth for a given area. This provides a key characteristic to target for measuring restoration performance.

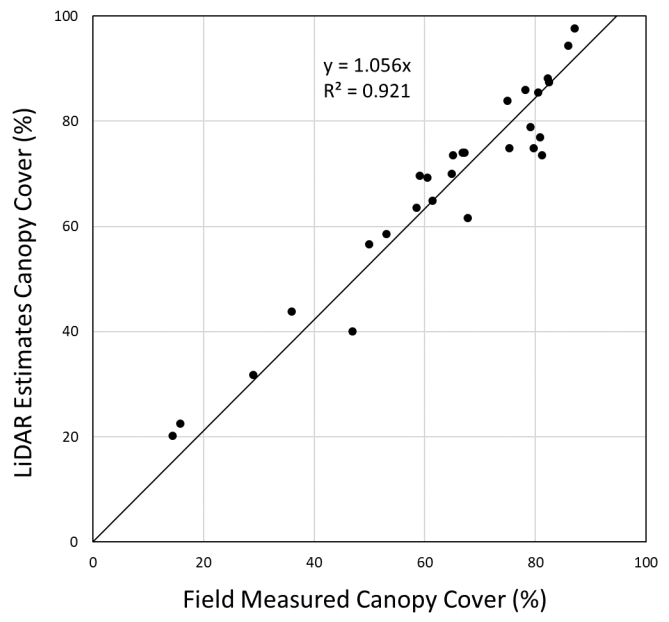

Figure 6 Comparison of canopy cover estimated from a LiDAR-derived CHM with field plot measurements; the line of best fit is forced through the origin 


\subsection{Leaf area index time series}

The availability of LAl satellite imagery makes it possible to measure the resilience of the restored areas by making comparisons of these LAl values with the surrounding forest and the forest that existed at that location prior to mining (Figure 7). In most cases, the restored mined forest has experienced disturbance from either fire or drought. This is evident by a drop in LAl followed by a recovery to pre-disturbance levels. In Figure 7, noticeable dips and recovery can be seen in the years following droughts experienced in 2006 and 2010. The peaks are indicative of increased vegetation growth as a result of favourable rainfall events prior to the imagery being taken.

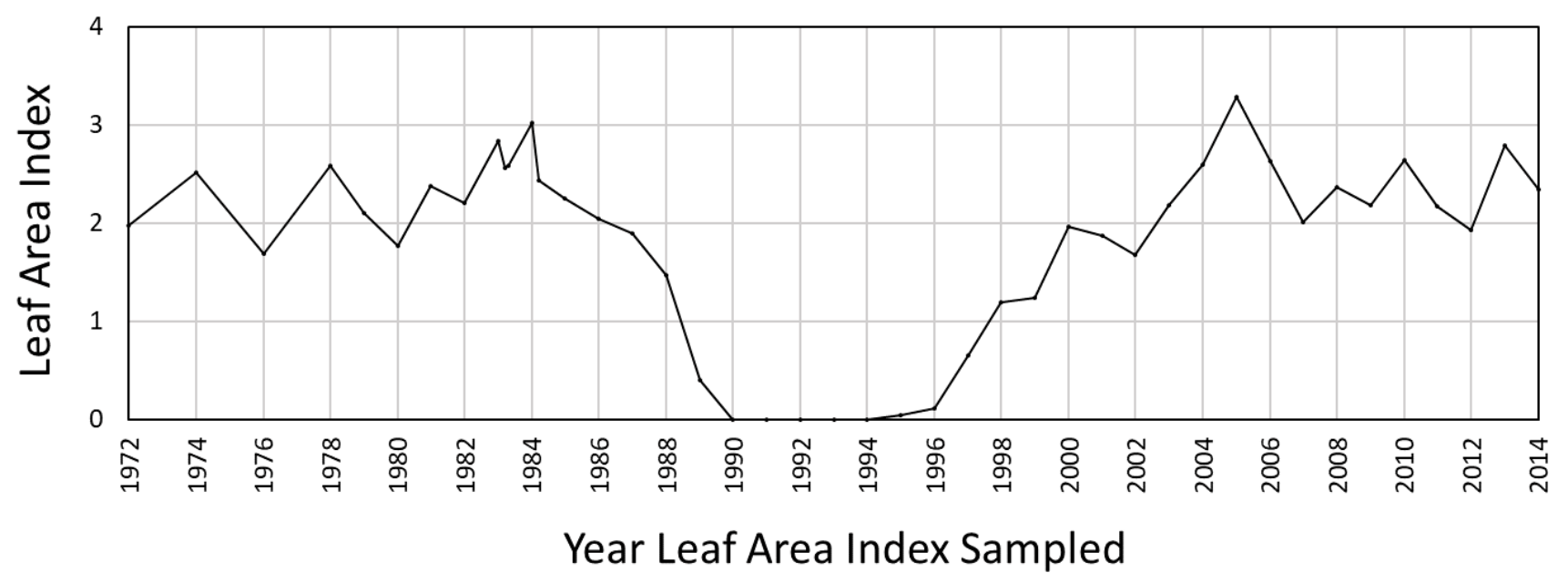

Figure 7 A time series of LAl for a mining pit restored in 1994

This investigation found that LAI can also be estimated from RPA multispectral imagery using a correlation between the LAI and an RPA-derived NDVI (Figure 8). The RPA was fitted with an incident light sensor to compensate for variation in sunlight. The multispectral sensor's collection of near-infrared and red spectral bands were used to calculate the NDVI. The soil line is calculated for each NDVI image from selected areas in the image of bare ground. The 0 value in the NDVI gradient represents no vegetation. The difference of these areas to 0 is used to calibrate the pixels in the NDVI image. If required, this method allows finer resolutions $(5 \mathrm{~cm})$ than Landsat $(30 \mathrm{~m})$. This is useful for areas that do not fit within the $30 \mathrm{~m}$ pixel limitation.

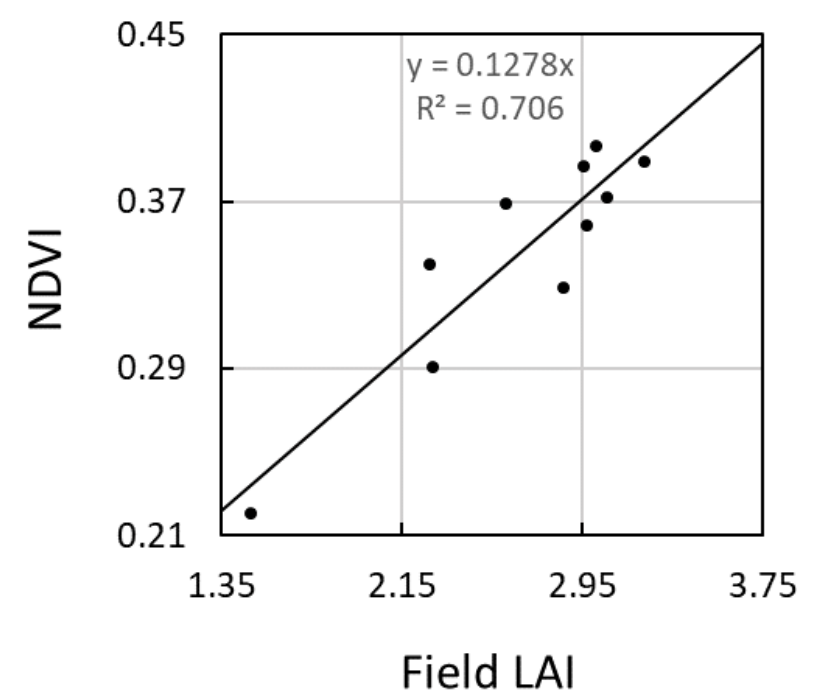

Figure 8 Correlation between field-measured LAI and RPA-collected NDVI 


\section{$6 \quad$ Landscape assessment}

\subsection{Bare ground}

Bare ground is measured by generating a grid from LiDAR pulses that have reached the forest floor. These are filtered to show cumulative areas that do not meet the requirements for specific bare ground completion criteria or for comparison measurements (Figure 9). Photogrammetry data collected from RPA also provides this information and can be processed in the same way. The decision on which technique to use depends on the circumstances requiring the data.

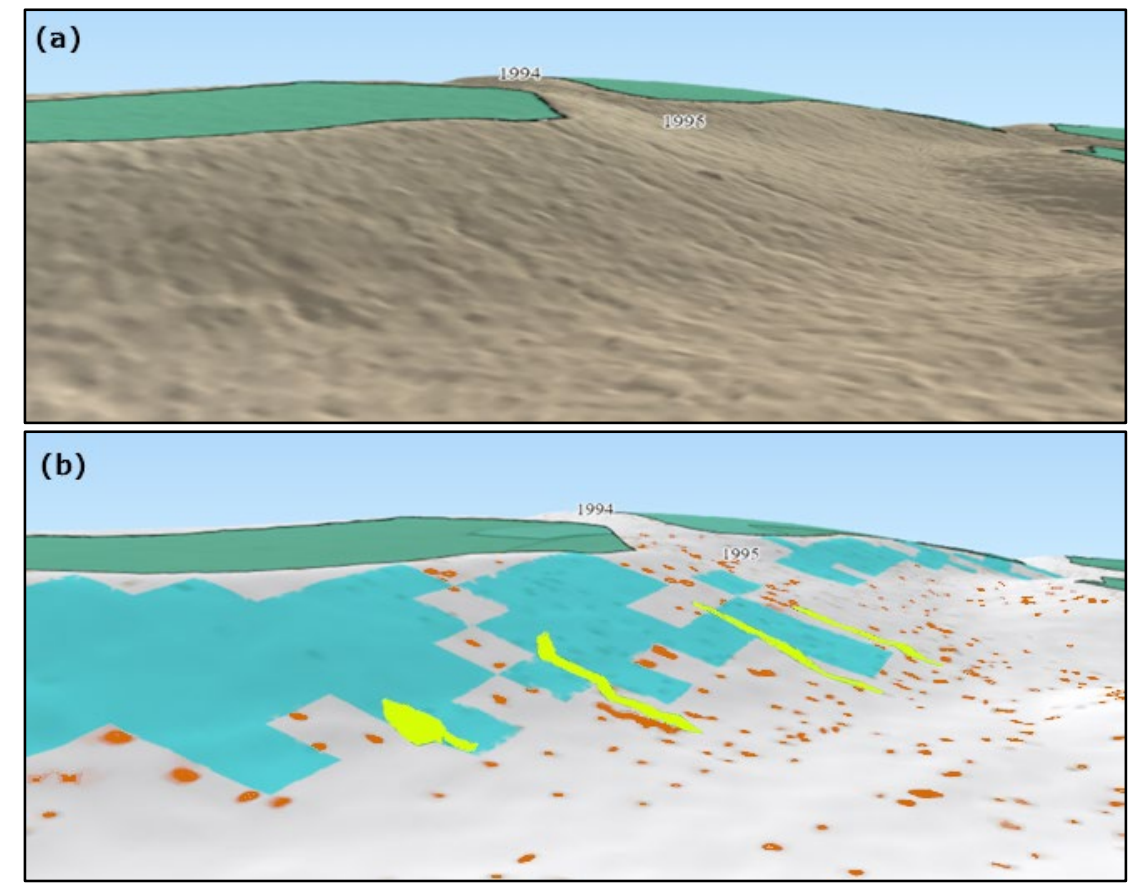

Figure 9 The digital elevation model (DEM) in (a) is of a 1995 forest restoration area, the green hill top is unmined forest, and the below model (b) is an assessment carried out on this area highlighting bare areas (orange) and completion criteria requirements not met for slope (blue) and erosion (yellow)

\subsection{Topographic assessments}

The ability for LiDAR to penetrate the different vegetation strata and collect ground information has made it a valuable tool in measuring undesired features in the terrain. The completion criteria specify particular dimensions for features that are unacceptable for sign-off. These include erosion gullies that are difficult to locate in the field and measure manually. The resolution from a LiDAR-generated DEM adequately renders these features for desktop measurements against specific completion criteria (Figure 9). This can also be done with RPA photogrammetry data in early restoration areas where vegetation coverage does not impede the ground visibility for spectral sensors.

\section{Conclusion}

The completion criteria have been designed to measure the restored forest in comparison to the surrounding unmined forest, including the measurement of self-sustaining characteristics of a forest ecosystem. The new techniques discussed in this study can comprehensively measure specific forest characteristics that describe forest structure. Further research is in progress to combine these techniques to stage restoration efforts on a trajectory toward a forest reference. Investigations are also in progress to develop tools and techniques to assess and document areas undergoing the early stages of restoration. 


\section{Acknowledgement}

The authors would like to acknowledge the contribution of an Australian Government Research Training Program Scholarship in supporting this research.

\section{References}

Abbott, I \& Loneragan, OW 1986, Ecology of Jarrah (Eucalyptus marginata) in the Northern Jarrah Forest of Western Australia, Department of Conservation and Land Management, Perth.

Cross, AT, Young, R, Nevill, P, McDonald, T, Prach, K, Aronson, J \& Dixon, KW 2018, 'Appropriate aspirations for effective post-mining restoration and rehabilitation: a response to Kaźmierczak et al.', Environmental Earth Sciences, vol. 77, no. 6, pp. 1-6.

Department of State Development 2015, Completion Criteria and Overview of Area Certification Process, viewed 3 February 2019, https://www.jtsi.wa.gov.au/docs/default-source/default-document-library/alcoa's-bauxite-mine-rehabilitation-program--completion-criteria-and-overview-of-area-certification-process---october-2015.pdf?sfvrsn=1fa26f1c_4

Elliott, P, Gardner, J, Allen, D \& Butcher, G 1996, 'Completion criteria for Alcoa of Australia Limited's bauxite mine rehabilitation', Proceedings of the 3rd International 21st Annual Minerals Council of Australia Environment Workshop, Minerals Council of Australia, Kingston, pp. 78-89.

Eysn, L, Hollaus, M, Lindberg, E, Berger, F, Monnet, J, Dalponte, M \& Pfeifer, N 2015, 'A benchmark of lidar-based single tree detection methods using heterogeneous forest data from the alpine space', Forests, vol. 6, no. 5, pp. 1721-1747.

Grant, C \& Koch, J 2007, 'Decommissioning Western Australia's first bauxite mine: co-evolving vegetation restoration techniques and targets', Ecological Management and Restoration, vol. 8, iss. 2, pp. 92-105.

Havel, JJ 1975, Site-Vegetation Mapping in the Northern Jarrah Forest (Darling Range). 1. Definition of Site-Vegetation Types, Forests Department of WA, Perth.

Jaskierniak, D, Kuczera, G, Benyon, R \& Wallace, L 2015, 'Using tree detection algorithms to predict stand sapwood area, basal area and stocking density in Eucalyptus regnans forest', Remote Sensing, vol. 7, no. 6, pp. 7298-7323.

Jaskierniak, DP, Lane, NJ, Robinson, A \& Lucieer, A 2011, 'Extracting LiDAR indices to characterise multilayered forest structure using mixture distribution functions', Remote Sensing of Environment, vol. 115, iss. 2, pp. 573-585.

Khosravipour, A, Skidmore, A, Isenburg, M, Wang, T \& Hussin, Y 2014, 'Generating pit-free canopy height models from airborne lidar', Photogrammetric Engineering \& Remote Sensing, vol. 80, no. 9, pp. 863-872.

Koch, JM 2007, 'Restoring a jarrah forest understorey vegetation after bauxite mining in Western Australia', Restoration Ecology, vol. 15 , iss. s4, pp. S26-S39.

Macfarlane, C, Grigg, A \& Daws, M 2017, 'A standardised Landsat time series (1973-2016) of forest leaf area index using pseudoinvariant features and spectral vegetation index isolines and a catchment hydrology application', Remote Sensing Applications: Society and Environment, vol. 6, https://doi.org/10.1016/j.rsase.2017.01.006

Macfarlane, C, Grigg, A \& Evangelista, C 2007, 'Estimating forest leaf area using cover and fullframe fisheye photography: Thinking inside the circle', Agricultural and Forest Meteorology, vol. 146, no. 1-2, pp. 1-12.

Pekin, B \& Macfarlane, C 2009, 'Measurement of crown cover and leaf area index using digital cover photography and its application to remote sensing', Remote Sensing, vol. 1, pp. 1298-1320.

Pirotti, F, Kobal, M, \& Roussel, JR 2017, 'A comparison of tree segmentation methods using very high density airborne laser scanner data', The International Archives of the Photogrammetry, Remote Sensing and Spatial Information Sciences, vol. 42, pp. 285-290.

Schut, AGT, Wardell-Johnson, GW, Yates, CJ, Keppel, G, Baran, I, Franklin, SE, Hopper, D, Van Niel, KP, Mucina, L \& Byrne, M 2014, 'Rapid characterisation of vegetation structure to predict refugia and climate change impacts across a global biodiversity hotspot', PLOS ONE, vol. 9, no. 1.

Wardell-Johnson, GW, Calver, M, Burrows, N \& Di Virgilio, G 2015, 'Integrating rehabilitation, restoration and conservation for a sustainable jarrah forest future during climate disruption', Pacific Conservation Biology, vol. 21, no. 3, pp. 1-11. 